\title{
Editorial
}

\section{Cadernos Nietzsche publicam a segunda parte do dossiê sobre Nietzsche e as Tradições Morais}

O presente volume dos Cadernos Nietzsche dá sequência à primeira parte do Dossiê Nietzsche e as Tradições morais, publicado no volume 37, n.1, em 2016. Os artigos aqui publicados seguem no geral a mesma tendência destacada na apresentação da primeira parte do Dossiê: eles contestam, por vias distintas, a visão que prevaleceu em boa parte da recepção de Nietzsche no século XX de que sua contribuição no campo da filosofia moral seria eminentemente negativa. As razões para tanto estão expostas na referida apresentação. A crítica radical de Nietzsche à moralidade e seu inegável engajamento normativo confrontam o intérprete com o desafio de articular esse duplo movimento, aparentemente contraditório, de seu pensamento, seja pela via de uma reconstrução sistemática de suas posições, seja mediante a reconstrução de seu diálogo com autores consagrados da tradição, ou mesmo à luz dos debates contemporâneos em filosofia moral, que desde a década de setenta têm tentado promover um alargamento de nossa compreensão da vida ética para além das opções oferecidas pelas teorias modernas hegemônicas representadas pela deontologia kantiana e pelo consequencialismo de matriz utilitarista. Os artigos aqui reunidos seguem, cada um à sua maneira, estas distintas estratégias.

O primeiro artigo, "A teoria nietzschiana da vontade", assinado por Brian Leiter, procura mostrar como Nietzsche, a partir de um exame detalhado da fenomenologia do querer, constrói um argumento a favor de sua tese revisionista de que a nossa experiência do querer 
não rastreia uma relação causal real com nossos atos, disso resultando o colapso da ideia mesma de responsabilidade moral no sentido exigido pelas teorias incompatibilistas da liberdade da vontade. Uma premissa importante do argumento de Nietzsche depende do que Leiter chama de Doutrina dos Tipos, segundo a qual todos os nossos pensamentos conscientes têm um estatuto de epifenômeno em relação à psicologia inconsciente e à fisiologia do agente, que por sua vez remete ao tipo psicofísico ao qual cada indivíduo deve ser vinculado. Leiter conclui seu artigo mostrando como a teoria nietzschiana da vontade antecipa certos resultados da psicologia empírica contemporânea.

$\mathrm{O}$ artigo de Alice Medrado, "Imoralismo - uma ética nietzschiana?", examina algumas tentativas recentes de reconstruir o que seria a contrapartida "positiva" da crítica de Nietzsche à moralidade, ou seja, o tipo de engajamento normativo que fundamentaria seu ataque à moral. Essas reconstruções têm atribuído a Nietzsche diferentes compromissos normativos, de modo que ele está próximo ora de um esteticismo, ora de algum tipo de utilitarismo, ora de uma ética das virtudes. Seu objetivo é avaliar em que medida estas reconstruções são capazes de capturar o que há de singular no que Nietzsche tem a nos dizer sobre ética e normatividade prática sem descuidar de certos compromissos essenciais de sua filosofia.

Em "Nietzsche sobre Helvétius: "o último grande acontecimento da moral", Oscar Rocha também adota a estratégia de confrontação com a tradição como forma de elucidar certas posições de Nietzsche. $\mathrm{O}$ artigo se concentra nas poucas menções de Nietzsche a Helvétius, tomando como fio condutor o que o filósofo diz acerca do pensador francês: que ele estaria à frente do "último grande acontecimento da moral". Rocha argumenta que essa frase deve ser entendida tanto positivamente - na medida em que Helvétius é visto por Nietzsche como proponente de um modelo mais realista de análise dos fenômenos morais - quanto negativamente - na medida em 
que ele é igualmente descrito como o precursor do mais recente desdobramento da moralidade de rebanho.

O artigo de Daniel Temp, "Nietzsche e a orientação perfeccionista de sua tentativa de estimar valores", procura oferecer uma reconstrução mais sistemática da posição normativa de Nietzsche, aceitando o desafio de articular de forma coerente o elemento crítico de sua filosofia com as formulações éticas construtivas. Seu objetivo é mostrar que as formulações positivas de Nietzsche guardam uma espécie de orientação normativa, ainda que em sentido mínimo. Esse minimalismo se deve ao fato de que qualquer juízo valorativo, aos olhos de Nietzsche, depende de um elemento subjetivo básico, mas ainda assim ele deve ser suficiente para assegurar sua força normativa. O autor procura caracterizar a posição final de Nietzsche como uma variante de perfeccionismo, seguindo certa tendência da literatura contemporânea, mas ao mesmo tempo dela se distanciando ao insistir no tipo peculiar de posição ocupada por Nietzsche no interior desta tradição.

O artigo de Rogério Lopes, "Filosofia como forma de vida: o embate com o ceticismo moderno", parte de uma estratégia distinta, ao confrontar Nietzsche com autores que não ocupam um lugar central na tradição moral. Lopes procura situar o projeto nietzschiano de retomada da filosofia como forma de vida, desenvolvido nas obras do período intermediário, no contexto dos debates em torno do ceticismo no início da modernidade. A tese de Lopes é que alguns impasses no projeto nietzschiano de retomada da noção de vida contemplativa, organizada em torno das noções de integridade intelectual e paixão do conhecimento, ganham em inteligibilidade se lidos à luz do confronto entre Montaigne e Pascal em torno da viabilidade de uma ética filosófica emancipada da religião. Ainda segundo o autor, algumas teses centrais de Nietzsche no campo da psicologia moral são formuladas em resposta direta às dificuldades levantadas por Pascal ao contestar a viabilidade desse projeto. 
Editorial

Finalizando o dossiê, o artigo de Maudemarie Clark, "A contribuição de Nietzsche para a ética", procura mostrar que o escopo da crítica de Nietzsche à moralidade, seu autoproclamado imoralismo, não abrange a totalidade de nossa experiência ética, mas uma interpretação particular dela, que resultou de um construto histórico cujas principais etapas são objeto de uma narrativa genealógica de orientação naturalista. Clark retoma de forma sucinta a tese, defendida por ela em outros momentos, de que a posição de Nietzsche não exclui a legitimidade de toda e qualquer categoria ética, nem recomenda a abolição de toda e qualquer regra para o governo de nossas relações interpessoais e sua internalização na forma de disposições que lhe confiram estabilidade. Sua posição final está bastante próxima da posição defendida por Bernard Williams.

Concluímos esta apresentação expressando mais uma vez nossos agradecimentos às inúmeras instituições e a todos aqueles que tornaram possível o evento científico que está na origem deste dossiê, assim como aqueles envolvidos nas diversas etapas de preparação deste número especial. O suporte financeiro para a realização do evento foi concedido pela CAPES, FAPEMIG, CNPq, PROEXUFMG, FAFICH, Programa de Pós-Graduação em Filosofia da UFMG, Programa de Mestrado em Estética e Filosofia da Arte da UFOP. Para a edição deste volume, agradecemos a todos os autores, aos tradutores, aos responsáveis pela revisão e diagramação da revista. Desejamos a todos uma leitura agradável e proveitosa.

***

Na segunda parte da revista, três artigos compõem a seção Varia. Em "Nietzsche, o perfeccionismo e a democracia: tensões entre Rawls, Cavell e os agonistas", João Kamradt defende que, no centro de seu pensamento político, Nietzsche incentiva a busca pela perfeição dos indivíduos. Para isso, persegue a disputa pelo 
significado do perfeccionismo do pensamento do filósofo por diferentes correntes. A seu ver, Rawls faz uma leitura de um perfeccionismo nietzschiano que é elitista, anti-igualitário e ligado a regimes aristocráticos. Essa foi uma leitura predominante do pensador. Mas, nos últimos 25 anos, surgiram outras interpretações para a busca pela perfeição nietzschiana. Uma defende um perfeccionismo moral no pensamento do autor, que seria igualitário e compatível com o ambiente democrático. Outra, mais recente, argumenta em prol de um perfeccionismo agonístico, visando a perpétua luta para superação de si mesmo como fundamental para o ambiente democrático. Adilson Felicio Feiler, em "A recepção de Nietzsche a partir do Index da biblioteca do Seminário Central de São Leopoldo/RS”, apresenta como O Index da biblioteca do Seminário Central Nossa Senhora da Conceição em São Leopoldo, no Rio Grande do Sul, guardou grande parte da obra filosófica que, nos anos que antecederam ao Concílio Vaticano II, esteve grandemente sob suspeita. Dentre este arsenal de obras, se destaca toda a obra de Nietzsche, da qual se ocupa este texto. Por mais paradoxal que pareça, Nietzsche, apesar da maneira controvertida com que tratava sobre temas como a cultura, a moral, o Cristianismo, Nietzsche, encontrou, no Seminário Central, diversos leitores. Estes, atraídos pela beleza de seu estilo e pela maneira impetuosa com que encarrava os problemas de sua época, levaram o pensamento de Nietzsche, em grande medida, a sério. Pode-se inferir a hipótese de que a recepção do pensamento de Nietzsche no Seminário Central foi se configurando, de certa forma, como ferramenta para se pensar os destinos futuros da Igreja Institucional. Paolo Stellino, no artigo "Projetivismo dos valores em Nietzsche", reivindica um lugar da filosofia nietzschiana na tradição filosófica do projetivismo. A seu ver, mesmo se Nietzsche é quase unanimemente ignorado nas obras dos especialistas nessa tradição, ele mantém, ao longo de seu desenvolvimento filosófico, uma posição que se pode com razão definir como "projetivista". 
Editorial

Conclui esta edição a Resenha que a professora argentina Mónica B. Cragnolini, da Universidade de Buenos Aires, fez para o Dicionário Nietzsche, publicado em 2016, primeira obra coletiva assinada pelo Grupo de Estudos Nietzsche (GEN). Cragnolini destaca a importância do Dicionário para os estudos nietzschianos na América do Sul, assim como as metodologias de trabalho realizadas pelo Grupo e que se deixam ver na obra.

Márcio José Silveira Lima Editor-Responsável Rogério Antônio Lopes Colaborador dos Cadernos Nietzsche, v.38, n.3 